\title{
Aplikasi Website Interaktif untuk Deteksi Tumbuh Kembang Anak
}

\author{
Interactive Website Application \\ for Pediatric Developmental Growth Detection \\ I Komang Setia Buana \\ STMIK STIKOM Bali \\ E-mail: buana@stikom-bali.ac.id
}

\begin{abstract}
Abstrak
Pertumbuhan dan perkembangan anak merupakan proses penting yang harus senantiasa dipantau agar optimal. Pemantauan bisa dilakukan oleh orangtua sebagai orang terdekat anak. Namun sayangnya tidak semua orangtua memiliki pengetahuan yang cukup tentang tumbuh kembang anak. Tidak semua orangtua juga memiliki waktu yang cukup untuk mengikuti sesi khusus pendidikan kesehatan tentang tumbuh kembang anak. Selain itu, informasi tumbuh kembang anak juga dibutuhkan oleh mahasiswa keperawatan untuk menunjang pembelajaran dan karena sifatnya interaktif, maka akan lebih menarik bagi mahasiswa. Berdasarkan hal tersebut, maka dibuatlah suatu media interaktif berbasis website yang berisi materi tumbuh kembang anak. Untuk merancang aplikasi ini menggunakan bahasa pemrograman PHP dengan software Xampp-win 32-1.7 platform Windows, MySQL 5.0.67, Notepad++, dan Macromedia Dreamweaver. Para pengguna dapat mengakses informasi mengenai tumbuh kembang anak sekaligus bisa menghitung Index Massa tubuh, berat badan ideal anak, penghitungan umur kronologis anak serta cara pemeriksaan menggunakan Denver II. Website ini diharapkan dapat memenuhi kebutuhan orangtua dan mahasiswa akan informasi tentang tumbuh kembang anak.
\end{abstract}

Kata Kunci - Tumbuh Kembang Anak, PHP, website.

The growth and development of children is an important process that must be constantly monitored for optimum results. Monitoring can be done by parents as the people closest to the child. Unfortunately, not all parents have enough knowledge about child development, not all parents also have enough time to attend special sessions of health education on child development. In addition, child development information is also needed by the nursing students to support learning and because it is interactive, it will be more interesting for students. Based on this, it was made a website based interactive media that contain material development of the child. In design application using the programming language PHP with Xampp software-win 321.7 Windows platform, MySQL 5.0.67, Notepad ++, and Macromedia Dreamweaver. The users can access information on child development as well able to calculate body mass index, ideal weight children, calculating chronological age of the child as well as how to use the Denver II examination. The website is expected to meet the needs of parents and students will be information about the development of the child.

Keywords - Growth dan Development Children, PHP, website. 


\section{PENDAHULUAN}

Pertumbuhan dan perkembangan anak merupakan hal yang penting untuk diperhatikan khususnya oleh orangtua. Sebagai orang terdekat anak, orangtua diharapkan mengetahui proses pertumbuhan dan perkembangan anak sehingga proses tumbuh kembang tersebut dapat berjalan dengan baik. Namun tidak semua orangtua mau dan mampu untuk mempelajari tentang tumbuh kembang anak. Kadangkala orangtua tidak memiliki waktu untuk menghadiri sesi pendidikan kesehatan khusus tentang tumbuh kembang anak, sehingga akses terhadap pengetahuan tentang tumbuh pada anak menjadi terbatas. Istilah tumbuh kembang sebenarnya mencakup dua peristiwa yang sifatnya berbeda, tetapi saling berkaitan dan sulit dipisahkan, yaitu pertumbuhan dan perkembangan. Pertumbuhan berkaitan dengan masalah perubahan dalam besar, jumlah, atau ukuran, yang bisa diukur dengan ukuran berat (gram, kilogram) dan ukuran panjang ( $\mathrm{cm}$, meter), sedangkan perkembangan adalah bertambahnya kemampuan dalam struktur dan fungsi tubuh yang lebih kompleks dari seluruh bagian tubuh sehingga masing-masing dapat memenuhi fungsinya [1]. Termasuk juga perkembangan emosi, intelektual dan tingkah laku sebagai hasil berinteraksi dengan lingkungannya [2]. Faktor-faktor yang mempengaruhi tumbuh kembang anak ada dua yaitu faktor genetik dan faktor lingkungan. Lingkungan yang baik akan menunjang tumbuh kembang anak, sebaliknya lingkungan yang kurang baik akan menghambat tumbuh kembangnya [3].

Pada era kecanggihan teknologi sekarang ini, keterbatasan waktu dapat diatasi dengan adanya media interaktif yang dapat diakses sewaktu-waktu tanpa harus menyediakan banyak waktu [4]. Media tersebut dituangkan dalam bentuk website yang diakses melalui jaringan internet. Media website tersebut dapat dibuat sesuai dengan kebutuhan, sehingga dapat menjadi suatu media untuk menyampaikan suatu ilmu dengan mudah dan juga interaktif. Luasnya jaringan internet yang ada saat ini memungkinkan kemudahan akses terhadap website, sehingga akan semakin banyak pula orang yang terpapar ilmu pengetahuan yang ada di website tersebut [5]. Aplikasi berbasis web adalah aplikasi yang dibuat dengan memanfatkan mekanisme dan aplikasi yang sudah ada pada sistem web (WWW), sistem web sebenarnya merupakan aplikasi yang berarsitektur client-server, menggunakan protokol HTTP (Hyper Text Transfer Protocol) dalam komunikasi antara client dan server yang mempunyai fungsi untuk mengambil atau menjalankan isi file dokumen web disisi server dan menampilkan disisi client [6].

Kelebihan dan kemudahan dari website inilah yang kemudian menjadi latar belakang dalam pembuatan website interaktif yang berisi tentang pertumbuhan dan perkembangan anak. Website ini dikatakan interaktif karena selain berisi materi umum tentang tumbuh kembang anak, pengunjung website juga dapat melakukan pengukuran pertumbuhan anak apakah sudah sesuai dengan usianya atau belum dengan penghitungan index massa tubuh, berat badan ideal pada anak. Website ini dibuat berdasarkan ide dari seorang pakar kesehatan anak Aries Chandra Ananditha, S.Kep.,Ns., M.Kep.,Sp.Kep.An. Orang tua yang tidak memahami tentang kesehatan tentu kesulitan mengetahui cara penghitungannya. Dalam website ini, orang tua tinggal memasukkan berat badan dan usia anak, orang tua dapat mengetahui indeks massa tubuh anaknya (tergolong kurang gizi, kurus, normal, gizi lebih, atau obesitas) serta orang tua dapat mengetahui berapakah berat badan anak normalnya berdasarkan usianya. Untuk mengetahui perkembangan anak, dapat digunakan dengan penghitungan umur kronologis pada anak dan cara pemeriksaan perkembangan menggunakan Denver II. Denver II merupakan alat pengkajian perkembangan pada anak [7]. Orang tua tinggal memasukkan tanggal lahir anak, maka akan keluar pertanyaan-pertanyaan terkait perkembangan anak berdasarkan usianya. Orang tua tinggal menjawab anak sudah bisa atau belum melakukan perkembangan tersebut. Pada hasil akhir penghitungan perkembangannya berdasarkan Denver II, akan diketahui apakah perkembangan anak normal, terlambat, atau perlu perhatian khusus. Sebenarnya penghitungan perkembangan dapat dilakukan dengan menggunakan Denver II. Namun pengisian Denver II hanya dapat dilakukan oleh tenaga kesehatan yang sudah terlatih. Website ini dimaksudkan agar orangtua dapat memperoleh informasi mengenai tumbuh kembang anak tanpa harus melalui pelatihan khusus. Orang tua tinggal memasukkan informasi yang diketahuinya maka kesimpulan tentang pertumbuhan dan 
perkembangan anaknya dapat diketahui dengan mudah. Kecukupan informasi mengenai tumbuh kembang anak ini diharapkan dapat meningkatkan kewaspadaan orangtua terhadap proses tumbuh kembang anak, sehingga bila ternyata anak mengalami gangguan tumbuh kembang orangtua dapat dengan segera dibawa ke fasilitas kesehatan terdekat.

Selain dimaksudkan untuk menambah pengetahuan orangtua, website ini juga berguna bagi tenaga kesehatan yang ingin memperkaya pengetahuannya mengenai tumbuh kembang anak. Saat ini kecenderungan orang lebih tertarik belajar melalui media interaktif seperti website ketimbang pembelajaran klasik. Oleh karena itu, dengan adanya website interaktif diharapkan dapat membantu dalam memahami proses pertumbuhan dan perkembangan anak.

\section{METODE PENELITIAN}

\subsection{Tempat dan Waktu Penelitian}

Tempat penelitian adalah STMIK STIKOM Bali, dengan alamat Jl. Raya Puputan No. 86 Renon - Denpasar, Bali

\subsection{Alur Analisis}

Sebelum mulai mengerjakan website interaktif untuk deteksi tumbuh kembang anak, dilakukan analisis kebutuhan serta perancangan dan pembuatan web terlebih dahulu. Analisis kebutuhan-kebutuhan terkait informasi tentang deteksi tumbuh kembang anak yang dibutuhkan baik oleh tenaga kesehatan, tenaga pendidik, maupun masyarakat sehingga dibutuhkan sebuah website interaktif yang memfasilitasinya. Website interaktif untuk mendeteksi tumbuh kembang anak merupakan sebuah aplikasi sistem informasi berbasis web yang terhubung dengan jaringan internet yang berguna untuk mempermudah para pengguna sistem (tenaga kesehatan, mahasiswa kesehatan, tenaga pendidik, maupun masyarakat umum) untuk mengakses data dan informasi tentang tumbuh kembang anak.

Perancangan dan pembuatan web ini memerlukan beberapa software yang saling mendukung diantaranya Xampp-win 32-1.7 platform Windows, MySQL 5.0.67, Notepad++, program aplikasi Macromedia Dreamweaver, serta web browser seperti Mozilla firefox, opera, maupun Internet Explorer.

Setelah proses desain selesai, maka perlu dipikirkan untuk domain dan web hostingnya. Nama domain web harus terdaftar. Ketika nama domain terdaftar, maka website tersebut akan teregister ke sebuah domain hosting yang besar. Selain itu informasi tentang situs web, termasuk IP akan disimpan pada server DNS. DNS (Domain Name System) akan menginformasikan ke semua komputer lain di internet tentang nama domain dan alamat web. Ketika memilih nama domain perlu dipertimbangkan tentang biaya, eksistensi nama domain, tujuan, serta kejelasan nama domain. Sedangkan untuk mempublikasikan web, maka dibutuhkan sebuah web hosting. Penawaran untuk hosting sudah mulai banyak sehingga perlu dipertimbangkan kebutuhan hosting dan anggaran dana yang dikeluarkan.

\subsubsection{Pemrograman Web}

Gambar 2.1 merupakan alur pemrograman website atau alur sistem ini. Alur dari penelitian ini dimulai dari analisa kebutuhan dengan cara melakukan observasi dan wawancara, setelah itu dilakukan proses perancangan dan pembuatan sistem. Dalam pembuatan sistem, website ini menggunakan Macromedia Dreamweaver sebagai aplikasi untuk mendesain website tersebut dan menggunakan bahasa pemrograman php. Kemudian ditambahkan formula khusus untuk melakukan perhitungan Indeks Massa Tubuh anak, Berat Badal Ideal anak, dan perkembangan anak. Setelah sistem selesai dibuat, dilakukan proses uji coba sistem. Pada tahap ujicoba jika aplikasi website dirasa tidak valid maka dilakukan proses perbaikan kembali, dan jika sudah dirasa benar maka website tersebut dipublikasi agar bisa diakses oleh semua orang. 


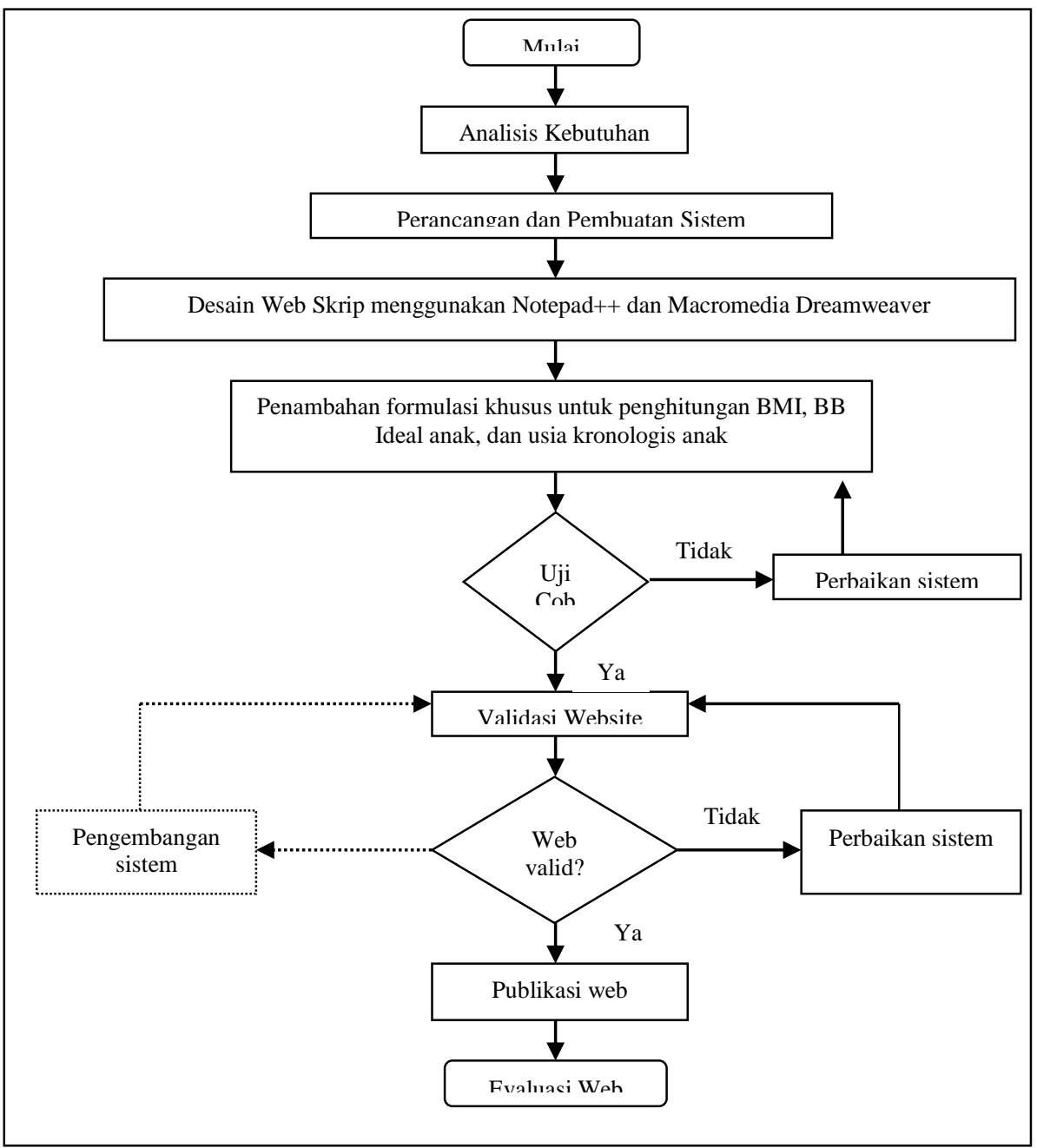

Gambar 1. Alur Pemrograman Website

\subsubsection{Cara Kerja Sistem}

Gambar 2.2 merupakan cara kerja sistem, dimulai dari membuka website menggunakan browser tertentu, menu-menu yang terdapat di dalam website tersebut serta perhitungan untuk melakukan deteksi tumbuh kembang anak. 
Citec Journal, Vol. 3, No. 2, Februari 2016 - April 2016

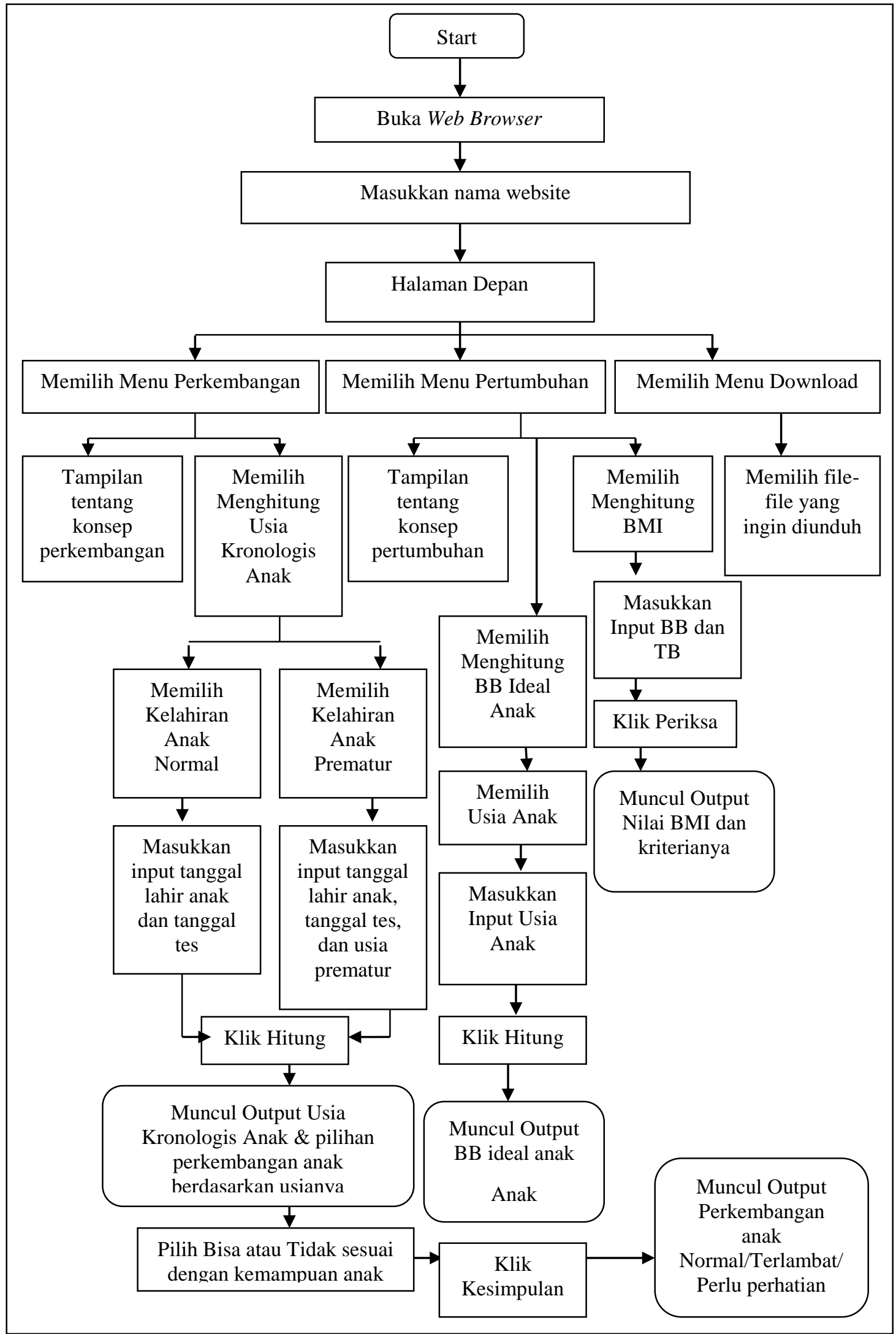

Gambar 2. Cara Kerja Sistem 


\subsubsection{Diagram Unified Modeling Language (UML)}

Unified Modeling Language adalah bahasa visualisasi, spesifikasi, konstruksi, dan dokumentasi. Penggunaan UML dapat memudahkan pembuatan model untuk semua jenis aplikasi piranti lunak. Aplikasi tersebut dapat berjalan pada piranti keras, sistem operasi dan jaringan apapun, serta ditulis dalam bahasa pemrograman apapun. Berikut ini adalah diagram-diagram yang merepresentasikan rancangan dari modul yang akan dibuat, meliputi use case diagram. Use case diagram menggambarkan fungsionalitas yang diharapkan dari sebuah sistem. Yang ditekankan adalah "apa" yang diperbuat sistem, dan bukan "bagaimana". Use Case Diagram untuk sistem ini ada dalam gambar 3.3. Dapat dilihat bahwa ada sebuah actor yaitu user yang melakukan tiga aktivitas, yaitu memilih menu perkembangan, menu pertumbuhan dan terakhir bisa memilih menu download. Menu perkembangan memuat info konsep perkembangan, menghitung usia kronologis, serta mengetahui kesimpulan perkembangan anak. Menu pertumbuhan terdapat info konsep pertumbuhan, menghitung BB Ideal Anak, dan Menghitung BMI. Sedangkan menu download. memuat file-file yang ada hubungannya dengan pertumbuhan dan perkembangan anak yang akan merujuk ke situs yang dipercaya dan dapat didownload. Berikut adalah Gambar Use case diagram:

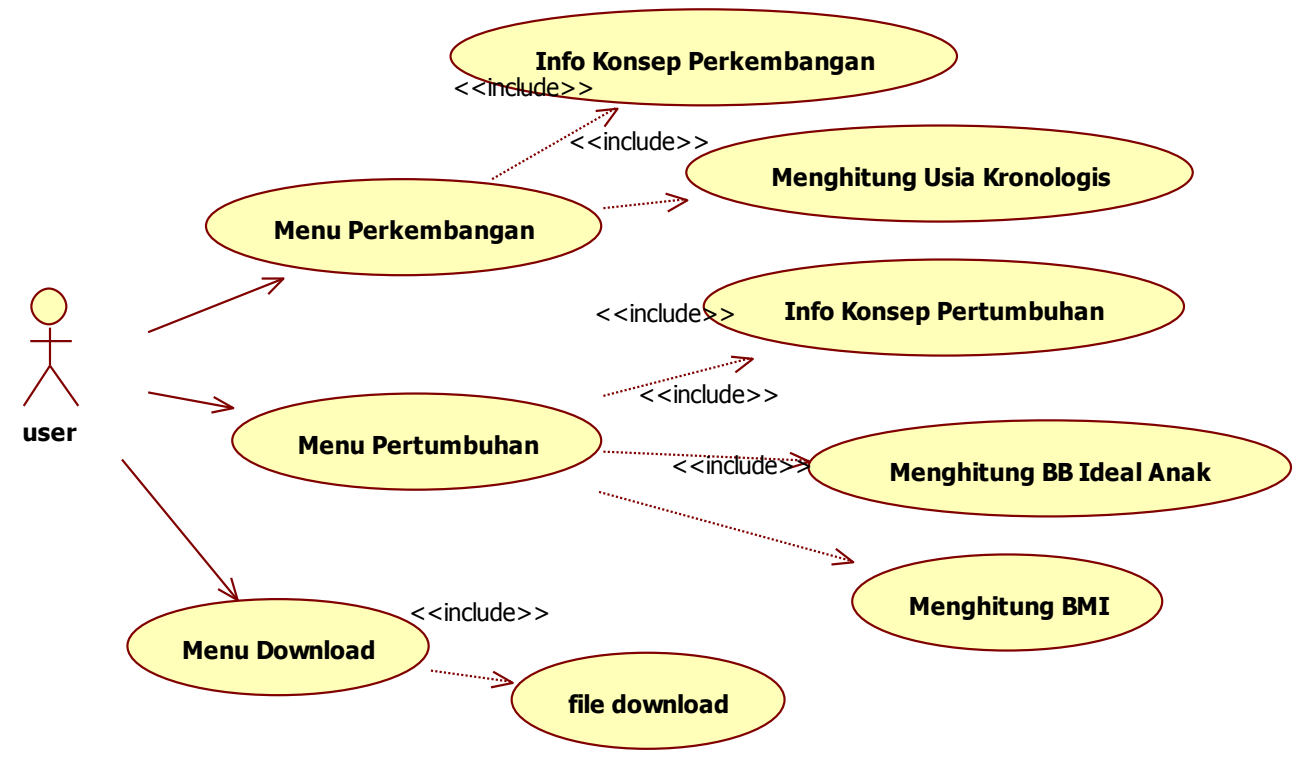

Gambar 3.Use Case Diagram Website

\section{HASIL DAN PEMBAHASAN}

\subsection{Peralatan yang dibutuhkan}

Pembuatan website interaktif deteksi tumbuh kembang anak memerlukan beberapa infrastruktur agar sistem yang dihasilkan dapat berjalan sesuai dengan yang diharapkan. Adapun infrastruktur-infrastruktur tersebut antara lain:

\subsubsection{Hardware}

Seperangkat komputer dengan spesifikasi minimum sebagai berikut:

a) Processor Intel, AMD

b) RAM $512 \mathrm{MB}$

c) Harddisk internal $80 \mathrm{~GB}$ 
Citec Journal, Vol. 3, No. 2, Februari 2016 - April 2016

ISSN: 2354-5771

\subsubsection{Software} lain:

Website interaktif ini menggunakan beberapa software yang saling mendukung, antara

a) Xampp-win 32-1.7 platform Windows

b) MySQL 5.0.67

c) Notepad++

d) Program aplikasi Macromedia Dreamweaver

e) Web browser seperti Mozilla Firefox, Google Chrome, Opera, maupun Internet Explorer.

\subsection{Implementasi Sistem}

\subsubsection{Menu Utama (website tumbuh kembang anak)}

Tampilan menu utama merupakan tampilan utama dari sistem. Pada saat pertama kali dibuka, akan memunculkan tampilan ini. Pada menu utama terdapat menu depan, perkembangan, pertumbuhan, dan menu download. Menu depan tersebut merupakan menu utama dari sistem.

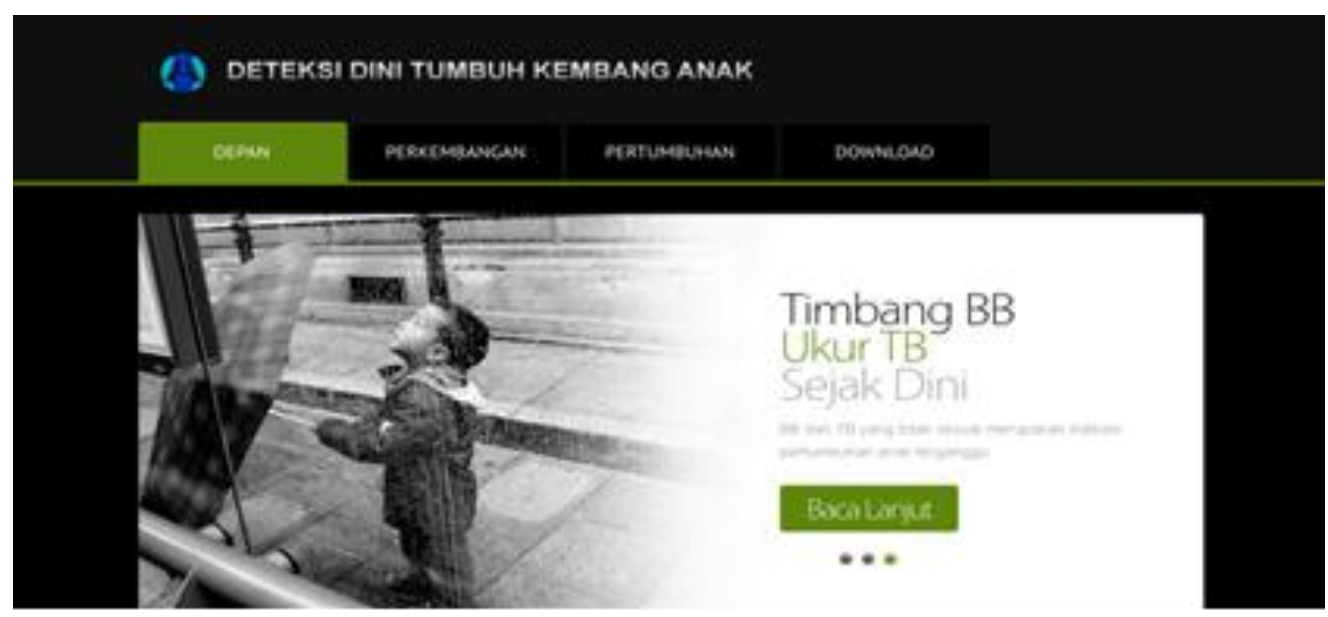

Gambar 4. Menu utama

\subsubsection{Menu Perkembangan}

Gambar 5 merupakan tampilan dari menu perkembangan. Menu ini berisi informasi yang bisa dilihat oleh pihak orangtua ataupun mahasiswa. Dalam menu ini, informasi yang disajikan dimulai dari penjelasan tentang apa itu perkembangan anak, kemudian adanya link yang bisa di klik oleh user untuk melihat masa perkembangan, dimulai dari 0-3 Tahun, 3-6 Tahun, 6-11 Tahun. Pada menu perkembangan ini juga terdapat perhitungan untuk Menghitung Usia Kronologis Anak pada pengukuran Denver II. Usia kronologi merupakan usia sebenarnya dari anak. 
Tampilan dari menu perkembangan bisa dilihat pada gambar di bawah ini:

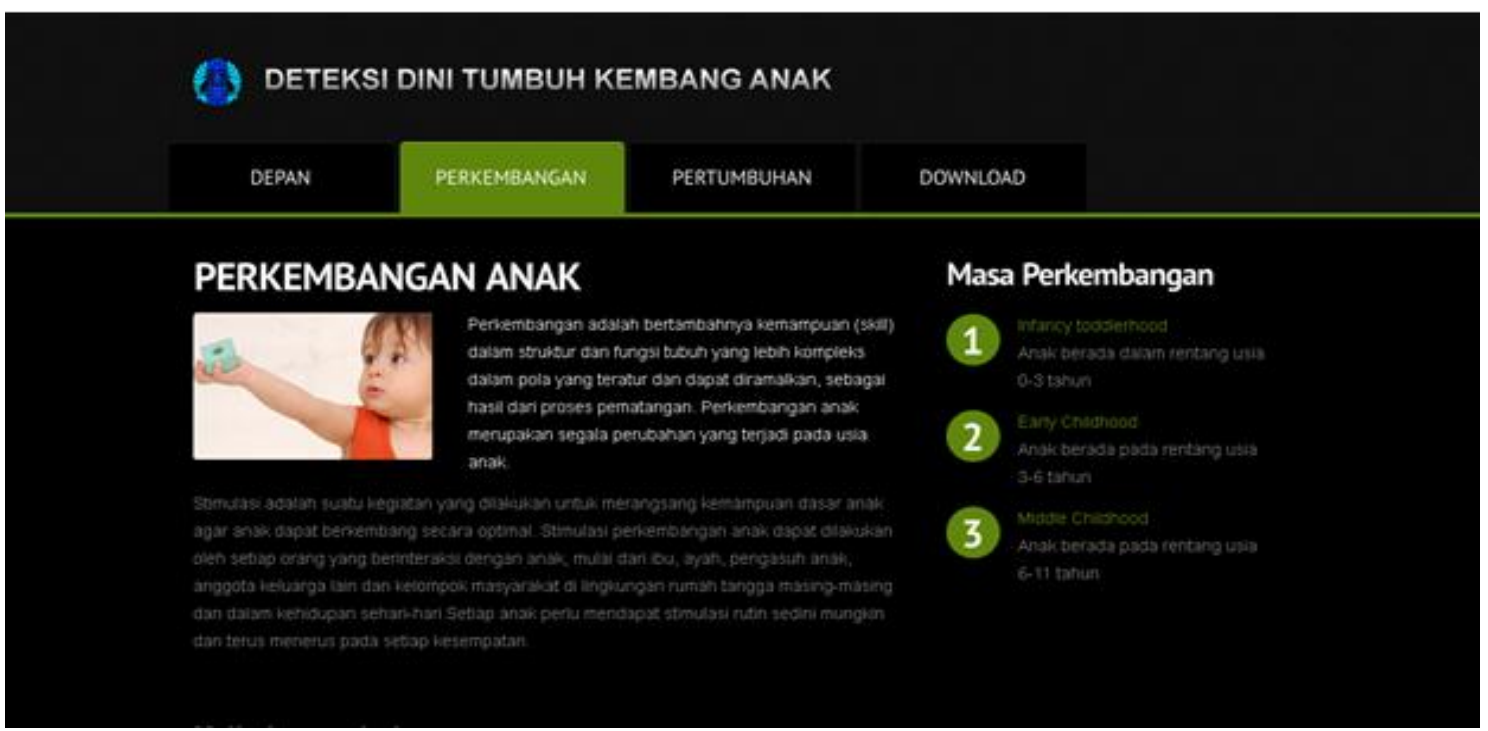

Gambar 5. Menu Perkembangan Anak

Berikutnya klik Cara Menghitung Usia Kronologis Anak pada pengukuran Denver II akan muncul tampilan berikut ini:

\section{Cara Menghitung Usia Kronologis Anak pada pengukuran Denver II}

- Jika Anak Lahir Normal

- Jika Anak Lahir Prematur

Gambar 6. Cara Menghitung Usia Kronologis Anak Pada Pengukuran Denver II

Gambar 6 merupakan menu untuk melakukan perhitungan usia kronologis menggunakan pengukuran Denver II. Pengukuran Denver II dibagi atas 2 kejadian, yaitu jika anak lahir normal dan jika anak lahir prematur. Untuk melakukan pengukuran Denver II dengan kondisi anak lahir normal, klik link jika anak lahir normal dan akan muncul tampilan seperti di bawah ini: 
Citec Journal, Vol. 3, No. 2, Februari 2016 - April 2016

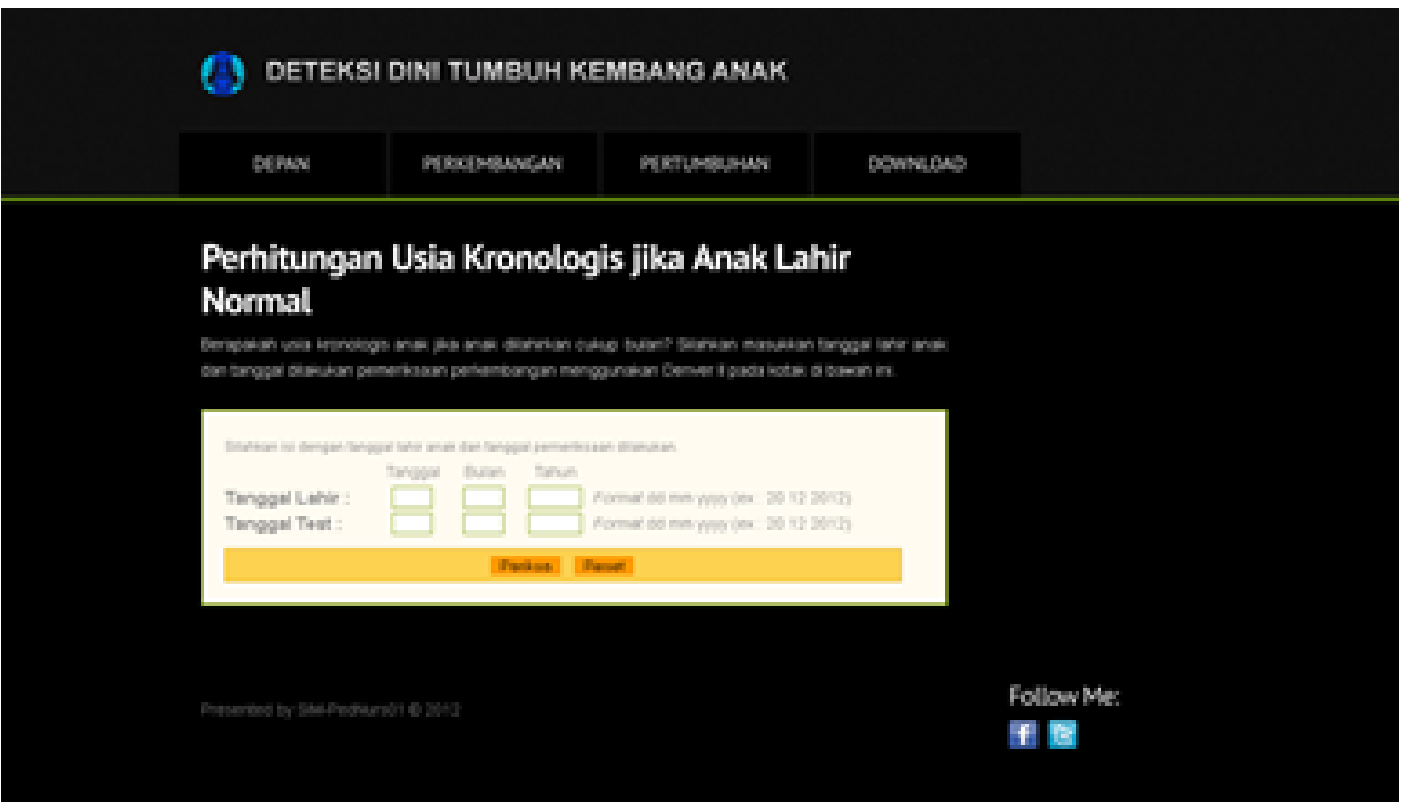

Gambar 7. Penghitungan Usia Kronologis jika Anak Lahir Normal

Untuk melakukan perhitungan, masukan tanggal lahir dan tanggal tes, kemudian klik tombol periksa. Proses perhitungan Denver II dengan kondisi normal langsung dihitung dari tanggal lahir sampai tanggal tes dan diasumsikan satu bulan itu 30 hari. Tombol reset pada gambar 7. berfungsi untuk mengosongkan data.

. Untuk melakukan pengukuran Denver II dengan kondisi anak lahir prematur, klik link jika anak lahir prematur dan akan muncul tampilan seperti di bawah ini:

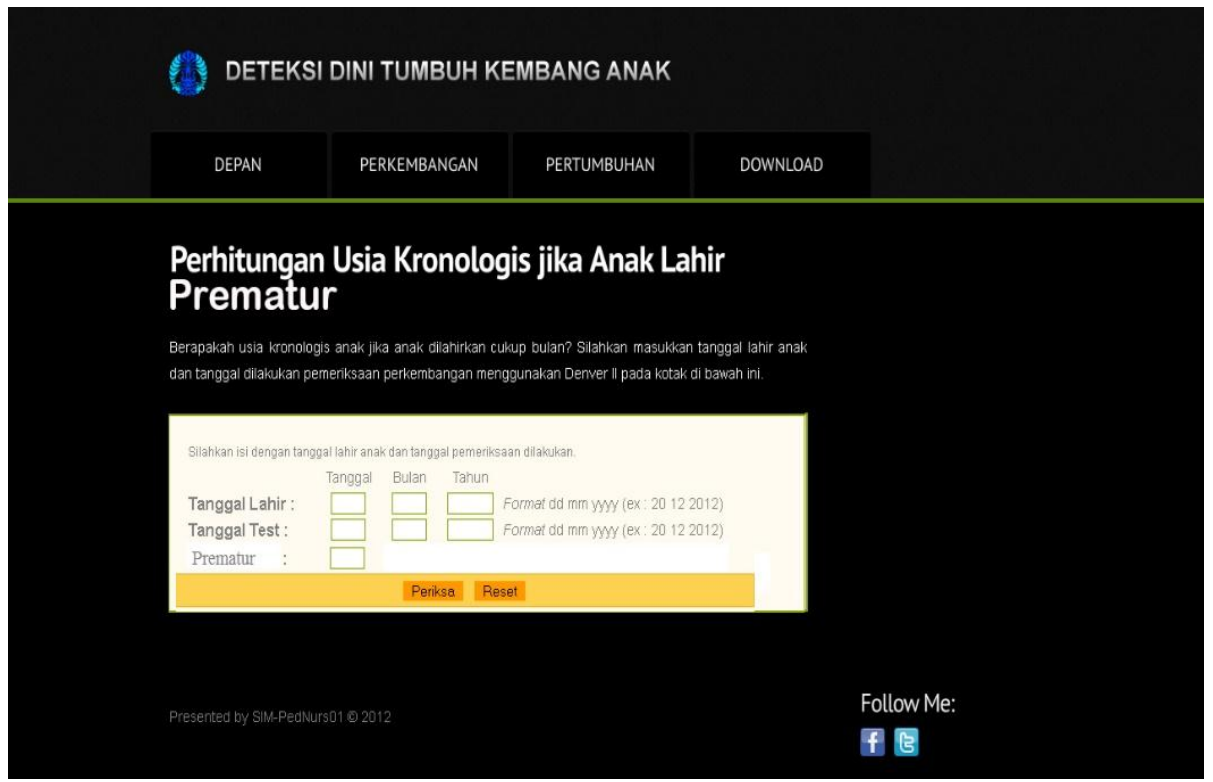

Gambar 8. Penghitungan Usia Kronologis jika Anak Lahir Prematur

Untuk melakukan perhitungan, masukkan tanggal lahir, tanggal tes dan berapa minggu prematur, kemudian klik tombol periksa. Proses perhitungan Denver II dengan kondisi prematur dihitung dari tanggal lahir sampai tanggal tes dan diasumsikan satu bulan itu 30 hari kemudian dkurangi prematur. Penyesuaian prematuritas dilakukan pada anak yang lahirnya maju lebih dari 2 minggu sebelum HPL Penyesuaian prematuritas tidak dilakukan setelah anak berusia 2 tahun. Tombol reset pada gambar 8 berfungsi untuk mengosongkan data. 


\subsubsection{Menu Pertumbuhan}

Pada menu pertumbuhan berisi informasi tentang pertumbuhan anak, apa pertumbuhan tersebut, ciri-cirinya seperti apa dan berisi kalkulator berat badan ideal yang digunakan untuk menghitung berat badan ideal untuk anak. Tampilan menu pertumbuhan seperti Gambar 9. :

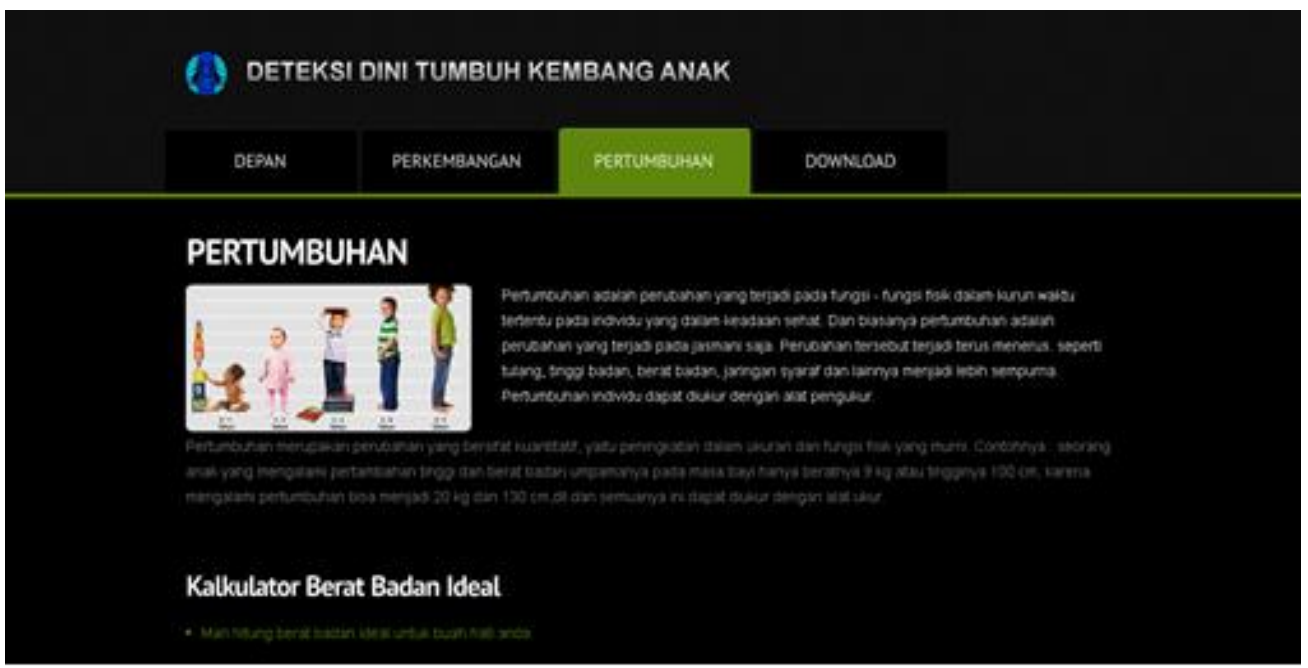

Gambar 9. Menu Pertumbuhan

Untuk melakukan perhitungan berat badan ideal, klik menu yang berada di kanan bawah yaitu menghitung berat badan ideal dan akan muncul tampilan seperti Gambar 10.

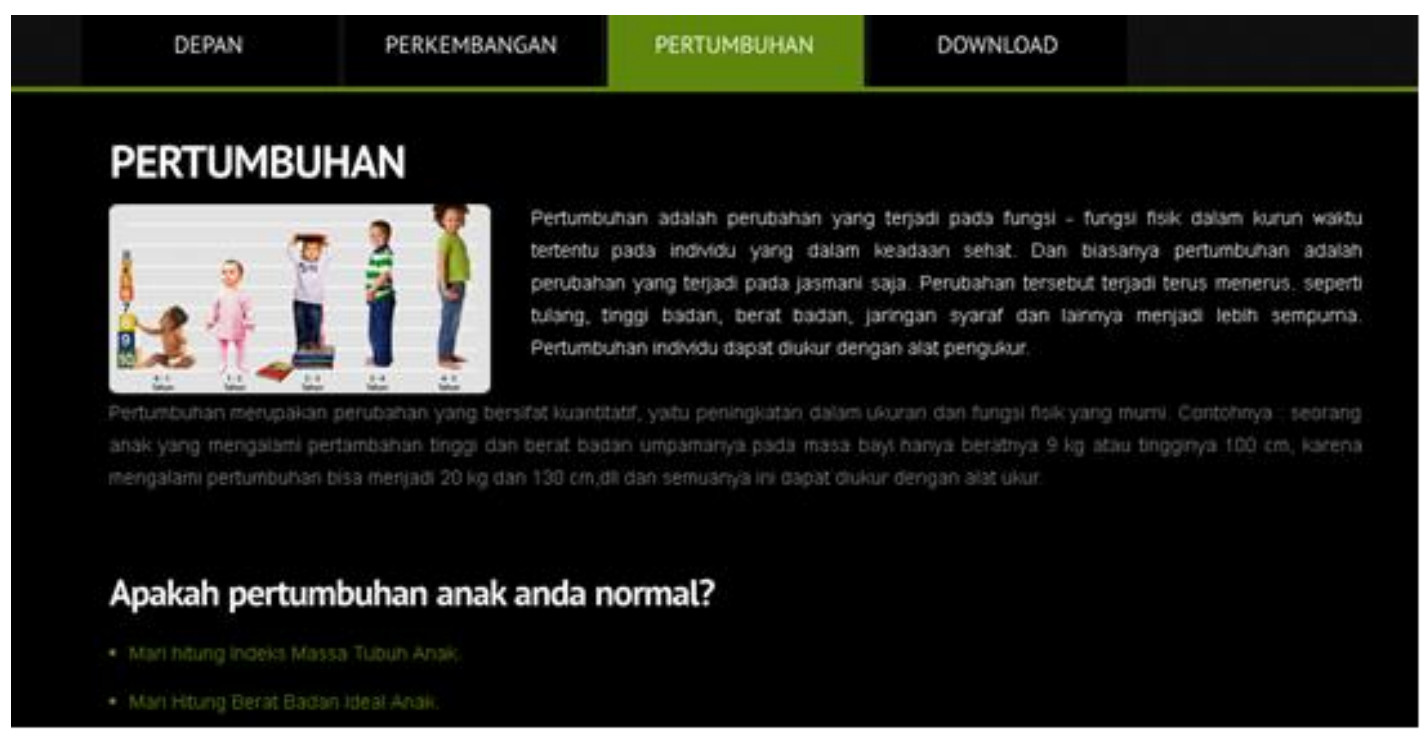

Gambar 11. Kalkulator Berat Badan Ideal

Gambar 11 merupakan menu untuk menghitung indeks masa tubuh anak dan menghitung berat badan ideal anak. Perhitungan terjadi jika menu tersebut diklik. Untuk melakukan perhitungan indeks masa tubuh anak maka klik menu "mari hitung indeks masa tubuh anak" yang berada di bawah kalimat "apakah pertumbuhan anak anda normal?" kemudian akan muncul seperti Gambar 12. 
Citec Journal, Vol. 3, No. 2, Februari 2016 - April 2016

\section{Perhitungan Indeks Masa Tubuh}

Apakah berat badan Anda ideal dan sehat? Silahkan coba alat bantu berikut untuk mengetahui apakah Anda termasuk kurus, normal, atau gemuk. Silahkan masukkan berat badan dan tinggi badan Anda pada kotak di bawah ini.

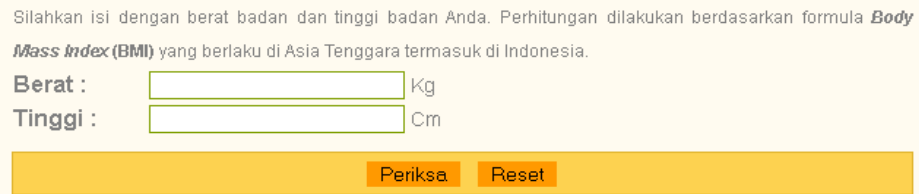

Gambar 12. Perhitungan Indeks Masa Tubuh

Untuk melakukan perhitungan indeks masa tubuh anak caranya adalah dengan memasukan berat badan dan tinggi badan, kemudian klik periksa maka akan muncul hasilnya. Untuk melakukan perhitungan berat badan ideal maka klik menu "mari hitung berat badan buah hati anda" maka akan muncul seperti gambar 13. :

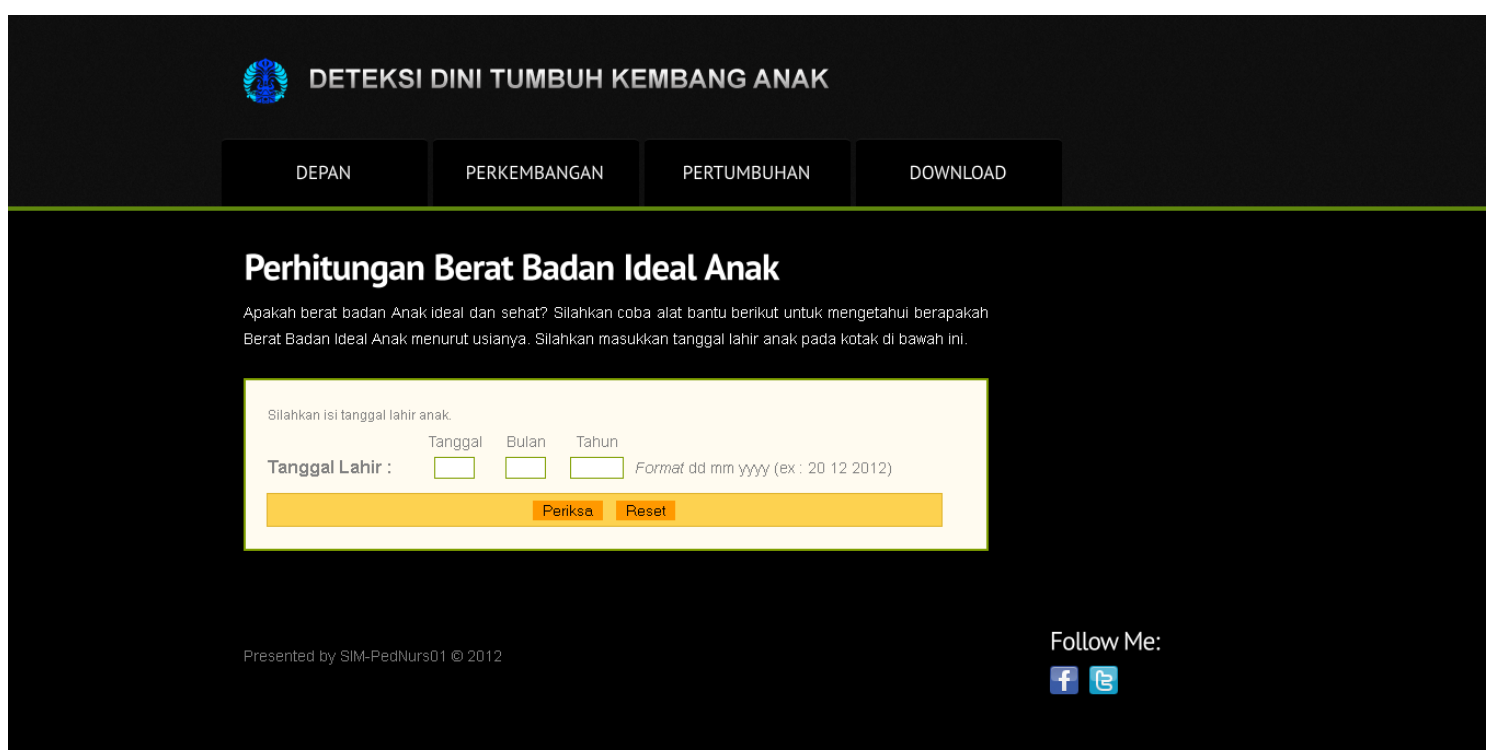

Gambar 13. Menghitung Berat Badan Ideal Anak

Untuk melakukan perhitungan berat badan ideal masukan tanggal lahir anak kemudian klik tombol periksa. Tombol reset berfungsi untuk menghapus isi textbox tanggal, bulan, dan tahun lahir.

\subsubsection{Menu Download}

Menu download berfungsi untuk mendownload file-file yang berisi informasi tentang tumbuh kembang anak, berita-berita terkini yang menyangkut tentang anak, dan perhitunganperhitungan berat, masa dan kesehatan anak. 
Tampilan menu download diperlihatkan pada Gambar 14. :

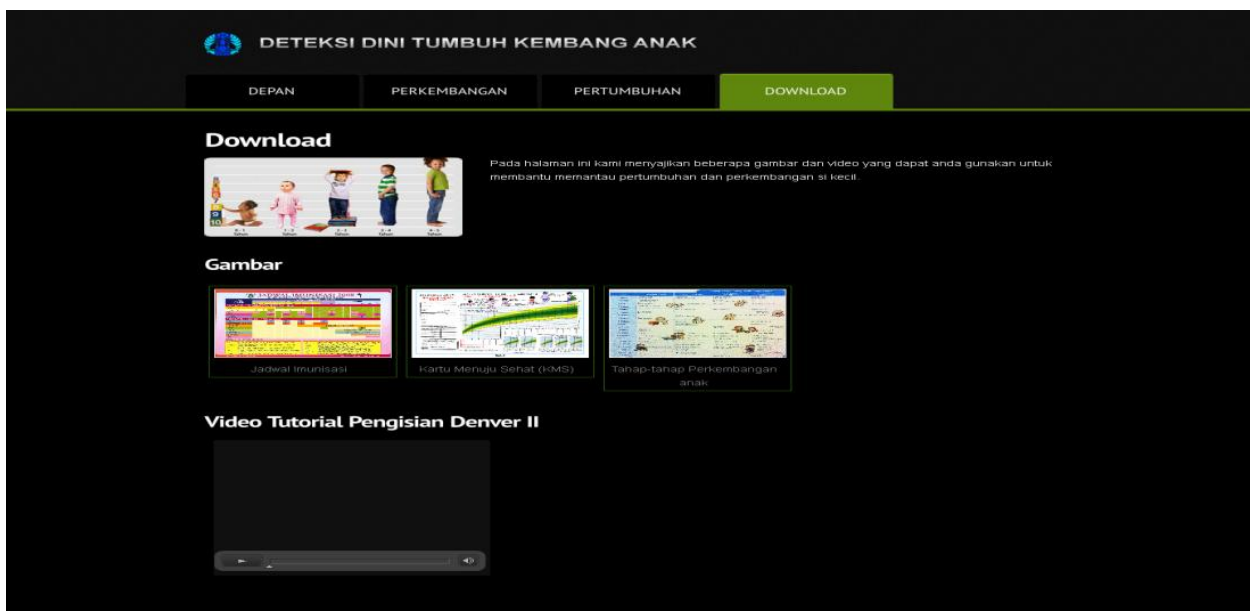

Gambar 14. Menu Download

\section{KESIMPULAN}

Kesimpulan yang dapat diambil dari penelitian ini adalah :

1. Aplikasi website interaktif untuk deteksi tumbuh kembang anak berjalan baik di browser mozilla firefox.

2. Aplikasi website ini dapat memudahkan pihak orangtua untuk mendapatkan data pertumbuhan dan kembang anak

3. Dapat melakukan penghitungan index massa tubuh, berat badan ideal pada anak serta penghitungan umur kronologis anak dan cara pemeriksaan perkembangan menggunakan Denver II.

4. Memudahkan mahasiswa keperawatan yang ingin memperkaya pengetahuannya mengenai tumbuh kembang anak.

\section{SARAN}

Saran yang dapat diberikan untuk penelitian ini adalah:

1. Desain tampilan perlu dibuat lebih menarik lagi.

2. Websitenya bersifat responsif artinya website tersebut tetap bagus tampilannya ketika dijalankan di mobile.

3. Adanya penambahan menu yaitu digunakan untuk menghitung kebutuhan anak seperti kebutuhan nutrisi dan cairan anak.

4. Dibuatkan aplikasi berbasis mobile yang bersifat offline sehingga memudahkan membuka aplikasi tanpa perlu koneksi internet.

\section{DAFTAR PUSTAKA}

[1] Thompson, L. A., Tuli, S. Y., Saliba, H., DiPietro, M., Nackashi, J. A., 2010, Improving developmental screening in pediatric resident education, Clinical Pediatrics Journal, No. 8, Vol. 49, Hal. 737-742.

[2] Benson, L. J., Baer, H. J., Kaelber, D. C., 2011, Screening for obesity-related complications among obese children and adolescent: 1999-2008. Obesity Journal, No. 5, Vol. 19, Hal. 10771082. 
Citec Journal, Vol. 3, No. 2, Februari 2016 - April 2016

[3] Ruffin, N. J., 2009, Understanding Growth and Development Patterns of Infants, http://pubs.ext.vt.edu/350/350-055/350-055.html

[4] Gentles, J. S., Lokker, C., McKibbon, K. A., 2010, Health information technology to facilitate communication involving health care providers, caregivers, and pediatric patients: a scoping review, Journal Of Medical Internet Research, No. 2, Vol. 12, Hal 1438-8871.

[5] Buana, I. K. S., 2014, Jago Pemrograman PHP untuk Pemula dan Orang Awam, Dunia Komputer.

[6] Nugroho, B., 2008, Aplikasi Pemrograman Web Dinamis dengan PHP dan MySQL (Studi Kasus, membuat Sistem Informasi Pengolahan Data Buku), Gava Media, Yogyakarta.

[7] Rocca, M. A., Rosenbloom, S. T., Spooner, A., Nordenberg, D., 2006, Development of a domain model for the pediatric growth charting process by mapping reference information model, AMIA Pediatric Journal, No. 2, Vol. 108, Hal 513-515. 